American Journal of Pharmaceutical Education 2020; 84 (9) Article 7829.

\title{
COMMENTARY
}

\section{We Are Educating Pharmacists, Not "PharmDs"}

\author{
Cynthia J. Boyle, PharmD \\ University of Maryland, School of Pharmacy, Baltimore, Maryland \\ Submitted August 27, 2019; accepted April 29, 2020; published September 2020.
}

Keywords: pharmacists, PharmDs, portrait, terminology, professional identity

Terminology can have profound implications for the profession and the Academy. One of the American Association of Colleges of Pharmacy (AACP) strategic priorities is to create a new portrait of pharmacists and pharmacy careers. ${ }^{1}$ The terms we use to describe our graduates and their work are pertinent to this new portrait and to the public's perspective. I hope to convince you in this commentary that we are educating pharmacists, not "PharmDs."

The profession of pharmacy has been through many transitional terms for pharmacists over the last few decades. My more seasoned colleagues and I remember the number of times we winced when we heard someone use the term "druggist," when we wanted to be identified with the more positive word "pharmacist." We also got distracted by the term "pharmacy doctor" or "PD" when we were debating the transition to the all Doctor of Pharmacy (PharmD) curriculum. This commentary is not intended to reignite the resentment between Bachelor of Science graduates and those who earned the Doctor of Pharmacy degree which included advanced experiential education for additional clinical training. We may still disagree on descriptions such as "clinical pharmacist," with some arguing that all pharmacists in patient care practice have clinical responsibilities. Gradually, the more limited term "retail pharmacy" has been replaced with "community pharmacy." Terms make a difference to internal and external audiences.

A recent article entitled "A Historical Discourse Analysis of Pharmacist Identity in Pharmacy Education"2 helps frame the challenges for our professional identity over time, and in turn our terminology. The authors describe five prominent identity discourses, including apothecary, dispenser, merchandiser, expert advisor, and health care provider. Graduates identify with these roles depending on the emphasis in health care and practice at the time of their graduation. The evolution from

Corresponding Author: Cynthia J. Boyle, University of Maryland, School of Pharmacy, 20 North Pine St., Baltimore, MD 21201. Tel: 410-706-5834. Email: cynthia.boyle@rx. umaryland.edu apothecary to provider is not fully sequential, and the health care provider theme "undervalues anything resembling the dispensing and merchant discourses by making them less legitimate." 2 It is no wonder that the profession struggles with inclusive terms when the pharmacist's role, especially in the corporate environment, is a hybrid of several prominent professional identities.

Why does it seem as if pharmacy and our pharmacy vocabulary are always at the proverbial crossroads? The entry-level Doctor of Pharmacy degree is a relatively recent phenomenon that evolved about two decades ago. The educational feat that was required to accomplish this transition is admirable. At the time of the transition, traditional practice sites remained primarily in community and health system settings, but there was an urgent need to scale up experiential sites in a variety of settings to meet patient care outcomes. The attempts to grow pharmacists' care services were not generally supported in state regulatory scopes of practice, and compensation based on products remains an issue. Diversification of expertise created a growth in certification credentials ${ }^{3}$ and a demand for residency experiences that far exceeds the supply. The almost constant change, uncertainty, and disruption are exhausting practitioners and educators alike.

As pharmacists' roles evolve to meet the needs of patients accessing health care through the Affordable Care Act, schools and colleges find themselves explaining these new roles to existing practitioners, legislators, health care partners, payors, alumni, and many more. I recall a specific example in which Maryland pharmacists were testifying to a General Assembly committee about the benefits of expanding pharmacists' scope of practice. One new legislator with an aviation background asked simply, "Can you just tell us what pharmacists can do?"

The Accreditation Council for Pharmacy Education (ACPE) conducted many town halls to gather input in preparation for the release of Standards 2016. A stakeholders' conference produced the mantra "practice ready, team ready." The guidance document developed for Standards 2016 stated, "Several healthcare disciplines 


\section{American Journal of Pharmaceutical Education 2020; 84 (9) Article 7829.}

have identified Entrustable Professional Activities to articulate the value of their disciplines to others (www.aamc.org/ cepaer). Similarly, pharmacy schools and colleges are encouraged to identify professional activities that their graduates perform routinely that help gain the trust of the healthcare team and the public they serve." ${ }^{.5}$ Both the legislator's question and the challenge from ACPE resonated as I charged Association committees with tasks during my term as AACP president. Through the collaboration, engagement, and persistence of the Academic Affairs Committee, entrustable professional activities (EPAs) for pharmacy were developed and deployed. ${ }^{6,7}$ All pharmacy graduates should be prepared and competent as patient care providers, interprofessional team members, and population health providers, as well as information masters, practice managers, and self-developers. Not every pharmacist will demonstrate all of these EPAs equally, but all EPAs can help pharmacists meet society's needs for optimal health care. These observable units of work become the common skill set and a common language and experience of pharmacists now being educated as health care providers. We are pharmacists, and this is what we do.

As we continue this cycle of diversifying, expanding, and refocusing pharmacy practice, it is important for the Academy to re-center and communicate clearly. Can we agree that pharmacy is a profession; a pharmacist is the person educated and licensed to practice in the profession; and the Doctor of Pharmacy degree (PharmD) is the current entry-level degree for the profession of pharmacy in the United States? It is inaccurate, imprecise, and often confusing to substitute "PharmD" for the word "pharmacist." We become members of the American Pharmacists Association, not the "American PharmD Association." Our degree is what we learned and earned, but our profession is what we do. Once you are aware of this misnomer, you see it everywhere. In saving four letters by using PharmD instead of pharmacist, professional identity and unity are lost.

This is not an uncommon occurrence. I hear our graduates introducing themselves as PharmDs, and our students voice their aspiration to become a "PharmD." In a background reading for the 2019-2020 Argus Commission, a family medicine article listed various health professions that worked in family physicians' practices. There it was again. The professions listed included nurse practitioner, registered nurse, physician assistant, licensed practical nurse, behavioral specialist, social worker, physical therapist/occupational therapist, psychiatrist, midwife, and PharmD. ${ }^{8}$ None of the other professions were identified by degree. We use this imprecise terminology, and others adopt it.
What is happening in other professions? The word doctor is confusing at a time when doctoral degrees have proliferated in physical therapy, nursing, and pharmacy, as well as medicine, long after the Doctor of Philosophy $(\mathrm{PhD})$ was established. In the profession of medicine, physician is the common term for medical doctors, who are further characterized by their focus, specialization, and distinctive skill sets. For example, an oncologist is a physician, and a pediatrician is a physician. Also, there are many designations for nurses, but most pertinent to this commentary is the growth of nurse practitioners who complete additional training so that they can assume advanced responsibilities for patient care. ${ }^{9}$ Are we actually using the term PharmD because we do not have an accepted term comparable to that of nurse practitioners? In fact, the identifier advanced practice pharmacist (APP) is being increasingly used across the country. ${ }^{10,11}$ Is APP preferable and acceptable for advanced pharmacy patient care practice as defined by practices or states?

Let us be clear. Our new portrait of pharmacists will be drawn by our collective efforts to enthusiastically portray our colleagues and their contributions to the health care team and public health. In doing so, we certainly can celebrate and promote the pharmacists who have earned credentials, such as board certifications and collaborative practice certifications. ${ }^{10}$ Pharmacy education and postgraduate programs and differentiated graduate degrees have produced practice-specific expertise which supports health care privileging and distinctive careers in law, public health, and education. Some graduates will choose not to become licensed and instead pursue a variety of creative endeavors. Those who earn their pharmacy licenses will become pharmacists. Central and common to all these paths is their foundation in pharmacy education. Pharmacist-lawyer. Critical Care Pharmacist. Pharmacist-educator. Nuclear pharmacist. Let the blended hyphens and specialty adjectives abound! In all the glorious variety of pharmacy schools and colleges, degrees, and programs, we are united by our profession and distinguished by our earned expertise, skills, and interests. We are educating pharmacists, not "PharmDs."

\section{REFERENCES}

1. American Association of Colleges of Pharmacy. Strategic Plan. https://www.aacp.org/article/strategic-plan Accessed August 31, 2020. 2. Kellar J, Paradis E, Cees PM, et al. A historical discourse analysis of pharmacist identity in pharmacy education. Am J Pharm Educ. 2020 ajpe 7864; DOI: 10.5688/ajpe 7864

3. Board Certification Specialties. Board of Pharmacy Specialties https://www.bpsweb.org. Accessed August 31, 2020.

4. Beardsley RS, Zorek JA, Zellmer WA, et al. Results of the preconference survey: ACPE invitational conference on advancing quality in pharmacy education. Am J Pharm Educ. 2013;77(3):Article 46. 


\section{American Journal of Pharmaceutical Education 2020; 84 (9) Article 7829.}

5. Guidance for Educational Outcomes: Standards 1-4. Guidance for Standards 2016. Accreditation Council for Pharmacy Education. https://www.acpe-accredit.org/pdf/Guidance forStandards2016FINAL.pdf Accessed August 31, 2020. 6. Haines ST, Pittenger AL, Stolte SK, et al. Core entrustable professional activities for new pharmacy graduates. Am J Pharm Educ. 2017;81(1):Article S2.

7. Pittenger AL, Copeland DA, Lacroix MM, et al. Entrustable professional activities implementation roadmap: report of the 2016-2017 Academic Affairs Standing Committee. Am J Pharm Educ. 2017;81(5):Article S4.

8. Bazemore A, Wingrove P, Peterson L et al. The diversity of providers on the family medicine team. Journal of the American
Board of Family Medicine. 2016;29(1):8-9. https://doi.org/10.3122/ jabfm.2016.01.150229. Accessed August 31, 2020.

9. Doctor of Nursing Practice. American Association of Colleges of Nursing. https://www.aacnnursing.org/DNP. Accessed August 31,2020

10. Murawski M, Villa KR, Dole EJ, et al. Advanced-practice pharmacists: practice characteristics and reimbursement of pharmacists certified for collaborative clinical practice in New Mexico and North Carolina. Am J Health Syst Pharm. 2011;68(24):2341-2350.11.

11. Advanced Practice Pharmacist. California State Board of Pharmacy. https://www.pharmacy.ca.gov/forms/app_app_pkt.pdf. August 31, 2020. 